\title{
Optimal Substantive Standards for Competition Authorities
}

December 2015

\section{Yannis Katsoulacos}

\author{
Professor of Economics, Department of Economics \\ Athens University of Economics and Business \\ 76 Patission str. 104 34, Athens, Greece, \\ Tel: +30 2108203348 \\ Fax: +302108223259
}

e-mail: ysk@hol.gr, katsoul@aueb.gr

\author{
Eleni Metsiou \\ PhD Candidate, Department of Economics \\ Athens University of Economics and Business \\ e-mail: emetsiou@,aueb.gr
}

\section{David Ulph}

Professor of Economics

School of Economics and Finance, University of St. Andrews \&

Director of the Scottish Institute for Research in Economics (SIRE)

e-mail: du1@st-andrews.ac.uk 


\begin{abstract}
$\underline{\text { Abstract }}$
Recent years have witnessed a significant resurgence in the debate concerning the optimal substantive standard to be used in the enforcement of competition law. One of the arguments proposed for using a Consumer Surplus standard, is that, when firms can choose from a number of mutually exclusive actions, it may induce firms to adopt actions that lead to a higher level of total welfare than would a Total Welfare standard. This important basic insight, initially due to Lyons (2002), has been discussed and extended in the recent literature always in the context of mergers. In this paper we generalise and re-examine this argument for any potentially anti-competitive action - we have in particular in mind actions often challenged as attempted monopolisation (abuse of dominance) or vertical restraints, taken by firms in different environments. We show that in the absence of any efficiencies the two standards lead to exactly the same outcomes but a choice between them becomes important in the presence of efficiencies. With positive marginal-cost reducing efficiencies we confirm the presence of what we term a Lyons-effect in our more general setting. We then examine how the choice of standard depends on a number of relevant parameters. Most important in terms of their policy implications are the results that the Consumer Surplus standard will be the optimal choice, when the extant market power is significant, when the size of marginal costreducing efficiency effects is large and when the difference in the market power raising effects of mutually exclusive actions is large. These results are important since they suggest that in all cases where significant extant market power is a prerequisite for the enforcement of Competition Law it is best to use a Consumer Surplus standard.
\end{abstract}

\title{
JEL Classification: L4 Antitrust Policy, K21 Antitrust Law
}

Keywords: Antitrust enforcement, Antitrust law, Consumer Surplus Standard, Substantive Standards, Total Welfare Standard. 


\section{Introduction and Brief Review}

Recent years have witnessed a significant resurgence in the theoretical and policy debate concerning the optimal substantive standard in the enforcement of competition law. As Baker and Salop (2015) note, the debate today is often framed as a choice between the consumer surplus and the total welfare standards, though other, including non-economic goals, have been proposed too ${ }^{1}$. While the debate goes on, Competition Authorities (CA) in EU and USA, appear to continue to use a Consumer Surplus (CS) standard instead of a Total Welfare (TW) standard for appraising firms' practices under competition law. Thus :

- In the EU, the Commission's 2008 Guidance Paper on Art. 102 EC $^{2}$ states (in par. 5) that the Commission "will focus on those types of conduct that are most harmful to consumers". Par. 19 reiterates that the aim is to protect consumer welfare and links the concept of "anticompetitive foreclosure" directly to consumer welfare.

- The latest version of Merger Guidelines in $\mathrm{US}^{3}$ clearly states that "the Agency considers whether cognizable efficiencies likely would be sufficient to reverse the merger's potential harm to consumers in the relevant market, e.g. by preventing price increases in that market" which explicitly suggest that when prices are raised because of a merger, then this merger should be banned irrespective of cost efficiencies for the merging firms. Only if cost savings are large enough so that they are passed through to consumers and prices do not raise a merger will be allowed.

\footnotetext{
${ }^{1}$ See, for earlier contributions, Besanko and Spulber (1993); Neven and Röller (2000); Lyons (2002); and, more recently, Padilla (2005); Carlton (2007); Farell and Katz (2006); Heyer (2006); Fridolfsson (2007); Pittman (2007); Salop (2010); Armstrong and Vickers (2010); Kaplow (2011); Baker (2013); Hovenkamp (2013); Lianos (2013); Blair and Sokol (2013); Fox et.al (1987), Farrell and Katz (2006), and other references in Baker and Salop (2015), footnote 52. The latter propose that the consumer surplus standard "also helps to address inequality" (p. 12). See also Warden (2014).

${ }^{2}$ Guidance on the Commission's Enforcement Priorities in Applying Article 102 EC Treaty to Abusive Exclusionary Conduct by Dominant Undertakings, Commission of the European Communities, Brussels, 3 December 2008.

${ }^{3}$ U.S. Department of Justice and the Federal Trade Commission, Horizontal Merger Guidelines, (last version issued in August 19, 2010) available at: http://www.justice.gov/atr/public/guidelines/horiz book/hmg1.html.
} 
- Salop (2010) after reviewing the US evidence associated with a large number of specific antitrust cases ${ }^{4}$ concludes that the standard that has been used and is still used in USA by antitrust authorities and by courts is the CS standard.

On the other hand, the authorities in Canada and Australia seem clearly to have been moving towards a TW standard. Thus, Section 96 of the Canadian Competition Act directs the Tribunal not to issue an order against a merger if "..(it) is likely to bring gains in efficiency that will be greater than and will offset, the effects of any prevention or lessening of

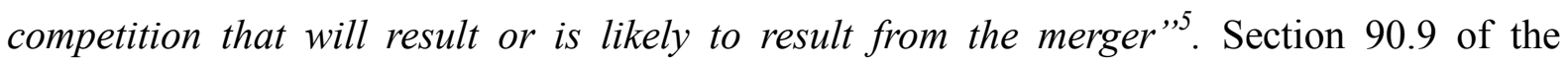
Competition Consumer Act 2010 in Australia states that an authorization for an acquisition may be granted if it "...would result, or be likely to result, in such a benefit to the public that the acquisition should be allowed to take place".

From a theoretical point of view the arguments for and against using a CS or a TW substantive standard have revolved around three main sets of issues, specifically ${ }^{6}$ :

1. Issues relating to distributional considerations

2. Dynamic issues

3. Issues emerging from the interaction between firms and competition authorities ${ }^{7}$. A number of reviews of all the above issues have appeared in recent years. Probably the clearest synopsis of arguments in favour of a CS standard is contained in Salop (2010) while that in favour of a TW standard (stressing dynamic issues) is contained in Carlton (2007) .

The focus of this paper is on the third set of issues mentioned above. In relation to this Salop (2010) argues that adopting the TW standard may lead firms to engage in inefficient

\footnotetext{
${ }^{4}$ Including mergers, horizontal agreements, predatory pricing, monopsony conduct, and harm to competitors (from mergers or exclusionary conduct).

${ }^{5}$ The recent Canadian Supreme Court merger decision on Tervito puts efficiencies even more front and center in merger enforcement procedures in Canada.

${ }^{6}$ Other than issues relating to administrability that could favor a CS standard - Hoverkamp (2013).

${ }^{7}$ Often modelled in the presence of information asymmetries.

${ }^{8}$ Other excellent reviews of the main arguments discussing the pros and cons without in the end taking a clear stance in favour of one of the standards are contained in Farrell and Katz (2006) and in Kaplow (2011). Also Motta (2004) and Pitman (2007).
} 
economic conduct that harms consumers and lowers aggregate welfare relative to the use of a CS standard. Farrell and Katz (2006) also provide an extensive discussion of this set of issues $^{9}$ and have stressed that even if we accept that the appropriate ultimate goal is that of total welfare maximization, there might nevertheless be good reasons why we would want the CAs to whom we delegate the task of enforcing competition policy to pursue a narrower objective of consumer surplus but the arguments in these economic analyses have "not yet been thoroughly explored"10.

Our analysis goes back to the insight of Lyons (2002) who examined firms choosing among mutually exclusive mergers anticipating the decision that a CA will take as to whether or not to allow the merger. Under some circumstances welfare may be higher if the CA uses a CS standard than if it uses a TW standard, since the former will deter firms from taking certain actions and lead them to take actions that are better from the point of view of overall welfare. Since Lyons (2002), a number of papers have discussed or further pursued this issue $^{11}$. However all this discussion has again been conducted in the context of mergers.

In this paper we make two main contributions. First, we generalize the analysis to the case where firms choose between mutually exclusive potentially anticompetitive actions of any type. Second, we examine how the choice of the standard depends on the environment of firms taking the action (such as the level of their extant market power) and on the size of cost efficiencies generated by the action. Concerning the type of action, we include here vertical restraints and actions often challenged as attempted monopolisation (or abuse of dominance in EU). Examples include the following:

(a) Marketing products under alternative tying/bundling arrangements.

(b) Offering different conditional rebate schemes.

\footnotetext{
${ }^{9}$ By reviewing also the papers by Lyons (2002), Besanko and Spulber (1993) and Neven and Röller (2005).

${ }^{10}$ Farrell and Katz (2006), p. 32.

${ }^{11}$ Apart from Farrell and Katz (2006) mentioned above see also Nocke and Whinston (2010, 2011); Armstrong and Vickers (2010).
} 
(c) Offering exclusive contracts with differing non-compete clauses.

(d) Engaging in vertical restraints of different types.

As for the case of mergers, it is well known that these actions will often entail both market power raising effects as well as potentially significant efficiency effects ${ }^{12}$, both of which form an integral part of our model below. Further, in our model, firms differ in the environment from which they come, which is specified in quite a general way, through the elasticity of demand in the competitive counterfactual and thus the price-raising potential of anticompetitive actions and through the extant market power that firms enjoy. Thus, the extent to which actions of some specific type influence prices, consumer surplus, profits and total welfare depends on the market-power raising and the (marginal) cost-reducing effects of these actions and also on the nature of the environment from which the firm taking the action comes. This allows us to consider also the implications of different environments and their distribution for the optimal choice of standards.

We find that when there are not mutually exclusive actions between which firms can choose the TW standard dominates the CS standard. Also, in the absence of any efficiencies the two standards lead to exactly the same outcomes. And, the TW standard (at least weakly) dominates the CS standard when actions do not generate marginal cost-reducing efficiency effects. However, a choice between the two standards becomes very important when there are positive marginal cost-reducing efficiencies ${ }^{13}$.

In the presence of marginal cost-reducing efficiency effects and considering first actions that are equivalent in terms of their cost reducing potential, total welfare for any given environment is smaller when higher-profit actions are chosen. And, while higher profit actions may pass a TW standard they may not pass a CS standard. So, as we show, there will

\footnotetext{
${ }^{12}$ See for example O'Donoghue and Padilla (2007) and Whinston (2006).

${ }^{13}$ Thus, our analysis does not support Motta's contention that "consumer and total welfare standards would not often imply very different decisions" (Motta, 2004, p.20) unless one assumes that efficiency effects are indeed rare, an assumption not supported by received wisdom about the effects of mergers, vertical restraints or indeed of many of the practices that can be used for attempted monopolisation.
} 
exist environments $^{14}$ for which having a CS standard may induce firms to choose lower-profit actions that result in higher welfare than would higher-profit actions, which would be chosen under a TW standard. This is what might be termed the Lyons Effect. However, there will be other environments for which welfare is higher when a TW standard is used, because the CS standard may be too strict and deter firms from taking any action even though there are welfare-enhancing actions that could have been chosen. We characterize the environments under which the Lyons effect will (or will not) emerge, and show that whether a CS standard generates higher welfare than a TW standard will depend on the distribution of firms across these different environments.

Most importantly, in terms of policy implications, we examine how the range of environments over which the Lyons-effect is present depends on parameters such as the extant market power of the firms, the size of marginal cost-reducing efficiency effects ${ }^{15}$ and the strength of the market power raising effect generated by different actions. With symmetric efficiencies across actions, we show that the arguments in favour of a CS standard are, ceteris paribus, more likely to be valid when the actions challenged are undertaken by firms that have significant market power to start with. Also, ceteris paribus, a CS standard is more likely to be optimal when we deal with actions (such as tying/bundling and vertical contracts) that, we understand on the basis of economic theory and evidence, can generate substantial efficiencies. These results are important since they suggest that in all cases where significant extant market power is a prerequisite for the enforcement of Competition Law it is best to use a CS standard, especially when we expect that actions are likely to generate substantial efficiencies ${ }^{16}$.

\footnotetext{
${ }^{14}$ Characterized by the elasticity in the competitive counterfactual and the extant market power.

${ }^{15}$ When these are symmetric across actions and the latter differ only in terms of their market power enhancing effects.

${ }^{16}$ These include essentially all cases other than the cases of horizontal collusive agreements or cartels for which, our analysis suggests that, the choice of standard is not important since they are not going to be associated with marginal cost-reducing efficiencies.
} 
The examination of actions differing also in marginal cost-reduction shows that, when there are significant asymmetries in the efficiencies of the different actions the TW standard will be the optimal choice.

The structure of the paper is as follows. In Section 2 we set out our model. In Section 3 we use this model to undertake a detailed comparison of CS and TW standards first assuming symmetric efficiency effects between mutually exclusive actions and then assuming that the actions also differ in terms of their marginal cost-reducing effects. Finally, Section 4 offers concluding remarks.

\section{A Model}

\subsection{Basic Assumptions}

Suppose that a number of firms from a range of environments are considering taking a type of action which will result in their increasing their market power and so their price-cost margin, but can also have some efficiency benefits, including driving down their marginal costs. There may be many potential actions of this type any one firm can take, each associated with particular levels of cost reduction and increase in the price-cost margin. In particular we will always allow for the default action of doing nothing and so neither increasing price nor lowering cost. Firms can choose which action within this class to take.

In making this decision firms take account of the possibility that a CA will assess their action and, if it is ruled to be anti-competitive in the light of the specific standard used by the CA, their action will be disallowed and they will have to pay a penalty.

Here we assume for simplicity that:

(i) all actions that are taken will be detected and assessed by the CA - in other words, the coverage or detection rate is unity; 
(ii) the CA can determine absolutely accurately whether or not the action is anticompetitive in the light of its standard - there are no Type I or Type II errors;

(iii) there are no delays by the $\mathrm{CA}$ in detecting anti-competitive actions and reaching decisions ${ }^{17}$.

We consider two different standards that the CA might use:

- a Consumer Surplus standard

- a Total Welfare standard that is based on the sum of both consumer and producer surplus $^{18}$ (profit).

We assume that firms know what standard the CA will use and have the capacity to determine what impact any action they take will have on the welfare standard (CS or TW standard) used by the CA. Given our assumptions about the capacity of the CA, firms will anticipate making negative (positive) profits if they take an action that produces a negative (positive) value of the CA's standard. Firms will choose the action that gives them the highest private benefit given the anticipated reaction of the CA.

We are interested in how social welfare depends on the standard being used by the CA. To consider this we will use the following model.

\subsection{The Model}

\subsubsection{Description of the counterfactual/default position}

Consider a typical firm that faces the following demand function:

$Q=1+\varepsilon-p, \varepsilon>0$

\footnotetext{
${ }^{17}$ For a recent paper discussing optimal antitrust enforcement in the presence of imperfect detection, decision errors and delays, see Katsoulacos and Ulph (2015).

${ }^{18}$ In this paper we only consider the profit of the firm that takes the action and not the loss/benefit of other firms' (e.g competitors or firms that produce supplementary products) that might be affected by the action. In a sequel paper we deal with this extension.
} 
Assume that the firm has a technology with constant marginal costs of production, $c$. Let $\left(p^{0}, Q^{0}, c^{0}\right)$ denote, respectively, the price, output and unit costs in the "but-for"/ default/counterfactual position. We use the normalisation that $c^{0}=1$.

We notice that if the firm has no market power in the default position, in which case

$$
p^{0}=c^{0}=1 \rightarrow Q^{0}=\varepsilon
$$

then $-\frac{d p}{d Q} \frac{Q^{0}}{P^{0}}=\varepsilon$ and so $\varepsilon$ denotes the inverse elasticity of demand evaluated in the competitive counterfactual price and output configuration. In what follows we will use $\varepsilon$ as a parameter that reflects the underlying competitiveness of the industry and so the potential for raising price that a firm will face if, given its initial cost, it can raise its market power so charge a price above marginal $\operatorname{cost}^{19}$. We could also say that $\varepsilon$ measures the incentive for raising price at the competitive counterfactual.

To allow for the possibility of extant market power, we want to allow for the possibility that the "but-for" price is above marginal cost, and so the initial price - cost margin lies somewhere between zero and that which would prevail under monopoly, which, it is easy to see, would be $\frac{\varepsilon}{2}$. However since we are interested in the possibility of firms taking anti-competitive actions that could increase their market power we want to exclude the possibility that the counterfactual situation is one of monopoly. So we assume that:

$$
p^{0}-1=\mu^{0} \varepsilon, 0 \leq \mu^{0}<(1 / 2)
$$

where $\mu^{0}$ is the parameter measuring the extent of market power in the counterfactual situation (extant market power).

\footnotetext{
${ }^{19}$ Easy to see that $\varepsilon$ measures the rate at which the firm's profits would increase if it raised price above $c^{0}=1$
} 
In what follows, we will denote the environment from which a firm comes by $e=\left(\varepsilon, \mu^{0}\right)$, and define the set of possible environments as ${ }^{20}$ :

$$
E=\left\{e=\left(\varepsilon, \mu^{0}\right) \mid \varepsilon>0,0 \leq \mu^{0}<\frac{1}{2}\right\} .
$$

\subsubsection{Potentially anticompetitive action}

Now suppose that, starting from this counterfactual position, the firm undertakes an action which both increases its market power - in a way specified below - but also has a pricereducing efficiency effect which lowers marginal costs by

$$
\Delta c=c^{o}-c^{1}=1-c^{1}, \quad 0 \leq \Delta c<1^{21}
$$

Now, given the demand function (1), if a firm with marginal costs $c^{1}=1-\Delta c$ were a monopolist, then its price-cost margin would be $\frac{\varepsilon+\Delta c}{2}$. So assume that the price-cost margin after taking the action is

$$
p^{1}-c^{1}=\mu(\varepsilon+\Delta c) \Rightarrow p^{1}=1+\mu \varepsilon-\Delta c(1-\mu)^{22}
$$

where $\mu, \quad 0 \leq \mu \leq \frac{1}{2}$ measures the market power that the firm exercises by taking this action.

In order for this action to be anti-competitive we assume that it would lead to an increase in price if there are no marginal cost-reducing efficiency effects (i.e. $\Delta c=0$ ). From (3) and (6) this requires that the degree of market power associated with this action, $\mu$, has to satisfy the condition: $\frac{1}{2} \geq \mu>\mu^{0}$.

\footnotetext{
${ }^{20}$ However, for clarity, whenever below we refer to a firm's "environment" but keeping extant market power constant we will be using $\varepsilon$ (rather than $e$ ).

${ }^{21}$ At some points in the later discussion we will want to allow for the possibility that these anti-competitive actions could have other cost-reducing efficiency effects, $\Delta F \geq 0$ which have no effect on marginal costs - and hence no effects on prices and consumer surplus - but lower fixed costs and so increase both profits and total welfare. However since our focus is on the effects of anti-competitive actions on market power and any associated efficiencies affecting marginal costs, we will not explicitly include the parameter $\Delta F$ in our description of an action.

${ }^{22}$ The associated output is $Q^{1}=(1-\mu)(\Delta c+\varepsilon)>0$
} 
In what follows an action will be denoted by $a=(\mu, \Delta c)$ and, for a firm from environment $e \in E$, the class of anti-competitive actions available to that firm will be:

$$
A\left(\mu^{0}\right)=\left\{\alpha=(\mu, \Delta c) \mid \frac{1}{2} \geq \mu>\mu^{0}, 0 \leq \Delta c<1\right\}
$$

Note that, of course, the degree of extant market power constrains the increment in market power that an anti-competitive action can have $\mathrm{e}^{23}$.

\subsubsection{Effect of action on price}

From (3) and (6), the change in price generated by an action can be expressed as:

$$
\Delta p(a, e)=p^{1}-p^{0}=-(1-\mu) \Delta c+\varepsilon\left(\mu-\mu^{0}\right)
$$

so we also have:

$\Delta Q(a, e)=-\Delta p=(1-\mu) \Delta c-\varepsilon\left(\mu-\mu^{0}\right)$

and

$Q^{1}(a, e)=Q^{0}+\Delta Q=(1-\mu)(\Delta c+\varepsilon)>0$

From (8), whether or not the price rises or falls depends in part on the nature of the action taken $(\mu$ and $\Delta c)$, and in part on the environment from which the firm comes - the parameters $\varepsilon$ and $\mu^{0}$. In particular, for any given $\mu>0$, and $\Delta c>0$, if initially there is no market power $\left(\mu^{0}=0\right.$ ), then in environments with very low inverse elasticities ( $\varepsilon$ when there is no initial market power) prices will fall, while in environments with very large inverse elasticities prices will rise. The presence of extant market power $\mu^{0}>0$ dampens a price rise and magnifies a price reduction ${ }^{24}$.

\subsubsection{Effects of action on consumer surplus, profit and total welfare}

\footnotetext{
${ }^{23}$ Though this is obvious, it is often seemingly forgotten, as when making unqualified statements that a pre-requisite for investigating a firm is that it has significant extant market power but for a liability finding we also require a significant increment in the market power.

${ }^{24}$ This is what we should expect as when the firm has extant market power the original product price will be high and this will lower the possibilities for raising prices even further.
} 
We can now calculate the change in consumer surplus, profits and hence total welfare when a typical firm takes a typical action.

The change in consumer surplus is:

$\Delta C S(a, e)=-\Delta p\left(Q^{0}+\frac{\Delta Q}{2}\right)$ and given $Q^{0}=\varepsilon\left(1-\mu^{0}\right)$

$\Delta C S(a, e)=-\frac{1}{2} \Delta p\left[2 \varepsilon\left(1-\mu^{0}\right)+\Delta Q\right]$

so since $\Delta Q=-\Delta p$, as expected, the sign of this will be driven entirely by the change in price.

Given (9), by substituting into the expression above:

$\Delta C S(a, e)=\frac{1}{2}\left[(1-\mu)(\Delta c+\varepsilon)-\varepsilon\left(1-\mu^{0}\right)\right]\left[(1-\mu)(\Delta c+\varepsilon)+\varepsilon\left(1-\mu^{0}\right)\right]$

or:

$\Delta \mathrm{CS}(\mathrm{a}, \mathrm{e})=\frac{1}{2}\left[(1-\mu)^{2}(\Delta c+\varepsilon)^{2}-\varepsilon^{2}\left(1-\mu^{0}\right)^{2}\right]$

The increase in profits (private benefit) from taking the action is:

$\Delta \Pi(a, e)=\left(p^{1}-c^{1}\right) Q^{1}-\left(p^{0}-1\right) Q^{0}+\Delta F=\left(p^{1}-c^{1}\right)\left(Q^{0}+\Delta Q\right)-\left(p^{0}-1\right) Q^{0}+\Delta F$

where $\Delta F$ are profit-enhancing efficiencies that do not lead to price reductions (such as fixed cost savings).

So from (10) and (6) and since $Q^{0}=\varepsilon\left(1-\mu^{0}\right)$,

$\Delta \Pi(a, e)=\mu(1-\mu)(\Delta c+\varepsilon)^{2}-\varepsilon^{2} \mu^{0}\left(1-\mu^{0}\right)+\Delta F$

The change in total welfare is just the change in consumer surplus, plus the change in profits (producer surplus):

$\Delta W(a, e)=-\Delta p\left(Q^{0}+\frac{\Delta Q}{2}\right)+\Delta \Pi$

and, making the relevant substitutions from above:

$\Delta W(a, e)=\varepsilon \Delta c\left(1-\mu^{0}\right)+\frac{1}{2}\left[\Delta c-\mu(\Delta c+\varepsilon)+\varepsilon \mu^{0}\right]\left[\Delta c+\mu(\Delta c+\varepsilon)+\varepsilon \mu^{0}\right]+\Delta F$

or $\Delta W(a, e)=\frac{1}{2}\left\{\left(1-\mu^{2}\right)(\Delta c+\varepsilon)^{2}-\left[1-\left(\mu^{0}\right)^{2}\right] \varepsilon^{2}\right\}+\Delta F\left(13^{\prime}\right)$ 
The first term in (13) is positive and shows the benefits to society from a reduction in costs if output were to remain at its original level. However, we need also to take into account the change in output. If price falls and consequently output increases then there is an unambiguous increase in welfare since the change in both consumer surplus and producer surplus are both positive. However, if the net result of the action is to drive prices up and so cause output to fall, then while society benefits from the fall in costs it loses from the reduction in output and overall welfare might fall. This will certainly happen when the reduction in marginal costs is very small ${ }^{25}$.

Note finally, the case where no action is taken. This can be thought of as taking the default action characterised by the pair $\left(\mu^{0}, 0\right)$, in which case the change in consumer surplus, profit and welfare are all zero irrespective of the environment from which a firm comes.

The expressions in (11), (12) and (13') show how the change in Consumer Surplus, Profits and Total Welfare depend on:

- the nature of a typical action as captured by the parameters $(\mu, \Delta c)$;

- the nature of the environment from which a firm comes, as captured by the parameters $\varepsilon$ and $\mu^{0}$.

We now want to understand in more detail the nature of this relationship.

\subsubsection{The properties of $\triangle C S, \Delta \Pi$ and $\Delta W$ and the case of a single trivial action}

For any non-trivial action $\left(\frac{1}{2}, 1\right) \gg(\mu, \Delta c) \gg\left(\mu^{0}, 0\right)$ we have the following results ${ }^{26}$ :

Lemma 1: The change in consumer surplus is, from (11), a strictly increasing function of $\Delta c$, a strictly decreasing function of $\mu$, a strictly concave quadratic function of $\varepsilon$ and $\mu^{0}$ (and so

\footnotetext{
${ }^{25}$ Unless of course the other, profit-enhancing efficiencies are large.

${ }^{26}$ In this section we concentrate on the effects of $\varepsilon$. The influence of the extant market power $\left(\mu^{0}\right)$ on $\Delta \mathrm{CS}$ and $\Delta \mathrm{W}$ is discussed in detail in Section 3 below.
} 
inverse U-shaped in $\varepsilon$ and in $\left.\mu^{0}\right)$. Also, if $\varepsilon<\underline{\varepsilon}=\frac{\Delta c(1-\mu)}{\mu-\mu^{0}}$ then the change in consumer surplus is positive, while if $\varepsilon>\underline{\varepsilon}=\frac{\Delta c(1-\mu)}{\mu-\mu^{0}}$ it is negative.

In other words, as we would expect:

- Consumers benefit from lower marginal costs and lose from an increase in the price-cost margin; and

- Using a CS standard, there is a critical value of the underlying competitiveness of the industry (as expressed by $\varepsilon$ ) such that the action is beneficial if the environment is potentially more competitive than that determined by this critical value, and harmful when it is potentially less competitive.

Lemma 2: For any environment and any non-trivial action, the change in profits is positive and is, from (12), a strictly increasing function of both $\Delta c$ and $\mu$ and also a strictly increasing but convex function of $\varepsilon$ and a strictly decreasing but convex function of $\mu^{0}$. So, as expected:

- Firms benefit from both lower costs and anything that allows them to charge a higher price-cost margin;

- A higher initial price-cost margin decreases the increase on the profits from an anticompetitive action $^{27}$.

- The more potentially uncompetitive is the environment (the bigger the $\varepsilon$ ) the bigger is the increase in profits.

Lemma 3: The change in total welfare is, from (13'), a strictly increasing function of $\Delta c$, a strictly decreasing function of $\mu$, a strictly increasing and strictly convex function of $\mu^{0}$ and a strictly concave quadratic function of $\varepsilon$ (and so inverse U-shaped in $\varepsilon$ ). If $\varepsilon<\underline{\varepsilon}=\frac{\Delta c(1-\mu)}{\mu-\mu^{0}}$

\footnotetext{
${ }^{27}$ The reason for this is because as we have seen from equation (8) as the extant market power increases it dampens a price rise and magnifies a price reduction.
} 
then the change in total welfare is positive. It is easy to see that there exists an $\bar{\varepsilon}>\underline{\varepsilon}$ such that the change in total welfare is positive if $\varepsilon<\bar{\varepsilon}$ and negative if $\varepsilon>\bar{\varepsilon}$. Assuming $\Delta F=0$, this is given by $\bar{\varepsilon}=\Delta c \frac{\left(1-\mu^{2}\right)+\sqrt{\left(1-\mu^{2}\right)\left(1-\left(\mu^{0}\right)^{2}\right)}}{\mu^{2}-\left(\mu^{0}\right)^{2}}$ which is greater than $\underline{\varepsilon}$. So:

- While everyone in society benefits from a reduction in marginal costs, the loss to consumers from an increase in market power and thus in the price-cost margin when $\varepsilon>\bar{\varepsilon}$ outweighs the benefit to firms and overall total welfare falls.

- Using a TW standard, there is a critical value of the inverse price elasticity of the competitive equilibrium, $\bar{\varepsilon}>\underline{\varepsilon}$, such that the action is beneficial if the environment is potentially more competitive than that determined by this critical value, and harmful when it is potentially less competitive.

- The critical value of the inverse price elasticity of the competitive position is higher for a TW standard than for a CS standard, so, as we would expect, there are environments which would be judged to be harmful using a CS standard but benign using a TW standard.

Note that the results above lead immediately to:

\section{Proposition 1}

If there is just a single non-trivial action that firms can take, then welfare is always higher under a TW standard than under a CS standard.

Proposition 1 can be easily understood by looking in Figure 1.The reason is as follows:

- When a firm with extant market power $\mu^{0}$ comes from an environment for which $\varepsilon<\underline{\varepsilon}$, the action will be allowed and taken under both CS and TW standards.

- When the firm with extant market power $\mu^{0}$ comes from an environment for which $\varepsilon>\bar{\varepsilon}$ then the action will not be allowed and so it will not be taken under neither a CS nor a TW standard. 
- However, when the firm comes from an environment for which $\underline{\varepsilon}<\varepsilon<\bar{\varepsilon}$ then the action will not be allowed under a CS standard but will be allowed under a TW standard and this will contribute positively to aggregate social welfare.

\section{(Figure 1 here)}

Proposition 1 tells us that when it is not likely that firms will have alternative mutually exclusive options it is best to use a TW standard.

\section{Comparison of standards in the presence of mutually exclusive actions}

Suppose now that there are more than one non-trivial mutually exclusive actions. Each action $j$ has a price-cost margin raising effect as expressed by parameter $\mu_{j}$ and a marginal cost efficiency effect expressed by parameter $\Delta c_{j}$. So, simplifying notation, equations (11), (12) and (13) (with $\Delta F=0$ ), now take the following form:

$$
\begin{aligned}
& \Delta \operatorname{CS}_{j}\left(a_{j}, e\right)=\frac{1}{2}\left[\left(1-\mu_{j}\right)^{2}\left(\Delta c_{j}+\varepsilon\right)^{2}-\varepsilon^{2}\left(1-\mu^{0}\right)^{2}\right] \\
& \Delta \Pi_{j}\left(a_{j}, e\right)=\mu_{j}\left(1-\mu_{j}\right)\left(\Delta c_{j}+\varepsilon\right)^{2}-\varepsilon^{2} \mu^{0}\left(1-\mu^{0}\right) \\
& \Delta W_{j}\left(a_{j}, e\right)=\varepsilon \Delta c_{j}\left(1-\mu^{0}\right)+\frac{1}{2}\left[\Delta c_{j}-\mu_{j}\left(\Delta c_{j}+\varepsilon\right)+\varepsilon \mu^{0}\right]\left[\Delta c_{j}+\mu_{j}\left(\Delta c_{j}+\varepsilon\right)+\varepsilon \mu^{0}\right]
\end{aligned}
$$

\subsection{Comparison of CSS and TWS for the case where efficiencies are the same across} actions

Assume further that just two actions are available with $a_{j}=\left(\mu_{j}, \Delta c_{j}\right)$ where $j=1,2$, and simplify by firstly confining attention to the case where they have the same value of $\Delta c \geq 0,\left(\Delta c_{1}=\Delta c_{2}=\Delta c\right)$ and consequently differ solely in $\mu$, the extent to which they increase the price-cost margin.

Consider first the case where $\Delta c=0$ (no marginal-cost reducing efficiencies). 


\section{Proposition 2}

Given two mutually exclusive actions with $0<\mu_{1}<\mu_{2}$ :

(i) in the absence of any efficiencies it makes absolutely no difference what standard an authority uses $^{28}$

(ii) in the absence of marginal cost-reducing efficiencies, the TW standard weakly dominates the CS standard.

This result can be easily seen to hold by comparing (11) to (13). When there are no efficiencies of any kind, then both $\triangle C S$ and $\triangle T W$ are negative for all values of $\varepsilon^{29}$. In this case, no action will be allowed under any standard. When, however, there are no marginal cost-reducing efficiencies $(\Delta c=0)$, but $\Delta F>0$, so there are other profit-enhancing efficiencies, then while $\Delta C S<0$ for all values of $\varepsilon, \Delta T W$ may well be positive for some $\varepsilon$. Thus, in this case it is better to use a TW standard since with such a standard some welfare enhancing actions will be allowed while with a CS standard all actions will be banned.

Consider next the case where there are marginal-cost reducing efficiencies: $\Delta c>0$. It is this case that the choice between a CS and a TW standard becomes very important. Depending on the environment in which actions are taken, the extant market power, the difference in the market power raising effects of actions and the size or asymmetries in the efficiencies, the two standards can lead to distinctly different results.

We assume that $0 \leq \mu^{0}<\mu_{1}<\mu_{2}<1 / 2$. So action 2 is more profitable than action 1 and so will be chosen whenever both are available (allowed), though that will lead to lower total welfare than the total welfare that could be reached if action 1 had been chosen. If we define $\underline{\varepsilon}_{j}=\underline{\varepsilon}\left(\mu_{j}, \Delta c\right), \bar{\varepsilon}_{j}=\bar{\varepsilon}\left(\mu_{j}, \Delta c\right), j=1,2$ then:

- $0<\underline{\varepsilon}_{j}<\bar{\varepsilon}_{j}, j=1,2$

\footnotetext{
${ }^{28}$ The significance of this result is of course best understood when the simplifying assumptions of perfect detection and no errors by the CA are relaxed. Under these assumptions, in the absence of any efficiencies firms will not take any action, irrespective of the substantive standard used by the CA.

${ }^{29}$ The latter is negative because the reduction in consumer surplus in (11) outweighs the increase in profit in (12).
} 
- $0<\underline{\varepsilon}_{2}<\underline{\varepsilon}_{1} ; \quad 0<\bar{\varepsilon}_{2}<\bar{\varepsilon}_{1}$

Figure 2 illustrates the two functions $\Delta W_{j}, j=1,2$ as functions of the inverse elasticity $\varepsilon$ (keeping $\mu^{0}$ constant) and also locates the points $\underline{\varepsilon}_{j}, \bar{\varepsilon}_{j} j=1,2$. In Figure 2 we use curves with solid lines to show the changes in consumer surplus, profits and total welfare for action 1 and with dashed lines for action 2.

(Figure 2 here)

By denoting with $\widehat{\Delta W}^{T W}(\varepsilon)$ and $\widehat{\Delta W}^{C S}(\varepsilon)$, the change in total welfare given the optimal choice of the action by the firm under a TW standard and a CS standard respectively we can see that:

- For $0<\varepsilon<\underline{\varepsilon_{2}}$ both actions 1 and 2 generate positive consumer surplus and hence positive total welfare and so both will be allowed under both standards. Hence, action 2 will be chosen, and so $\widehat{\Delta W}^{C S}(\varepsilon)=\widehat{\Delta W}^{T W}(\varepsilon)=\Delta W_{2}(\varepsilon)$

- For $\underline{\varepsilon}_{2}<\varepsilon<\underline{\varepsilon}_{1}$ only action 1 generates positive consumer surplus, though both will generate positive total welfare. So action 1 will be chosen by firms under a CS criterion while action 2 will be chosen under a TW criterion. So we have $\widehat{\Delta W}^{\mathrm{CS}}(\varepsilon)=\Delta \mathrm{W}_{1}(\varepsilon)>\Delta \mathrm{W}_{2}(\varepsilon)=\widehat{\Delta \mathrm{W}}^{\mathrm{TW}}(\varepsilon)$. So a CS standard generates higher welfare than a TW standard in this range of environments. This is the Lyons effect.

- For $\underline{\varepsilon}_{1}<\varepsilon<\bar{\varepsilon}_{2}$ neither action generates positive consumer surplus, and so neither would be chosen by firms under a CS standard. However, both generate positive total welfare and so since both would be available under such a standard, action 2 will be chosen. Hence on this interval, welfare is higher under a TW standard since $\widehat{\Delta W}^{\mathrm{TW}}(\varepsilon)=\Delta \mathrm{W}_{2}(\varepsilon)>0=\widehat{\Delta W}^{\mathrm{CS}}(\varepsilon)$.

- For $\bar{\varepsilon}_{2}<\varepsilon<\bar{\varepsilon}_{1}$ only action 1 generates positive total welfare and so action 1 will be chosen under a TW criterion, but since neither action generates positive consumer 
surplus on this interval neither will be chosen under a CS criterion. Hence, in this range of environments, welfare is higher under a TW standard since $\widehat{\Delta W}^{T W}(\varepsilon)=\Delta W_{1}(\varepsilon)>0=\widehat{\Delta W}^{C S}(\varepsilon)$.

- Finally, for $\varepsilon>\bar{\varepsilon}_{1}$ neither action generates positive welfare and so, a fortiori, neither generates positive consumer surplus. Hence under both standards only the default action will be chosen, generating zero welfare, so on this interval $\widehat{\Delta W}^{C S}(\varepsilon)=\widehat{\Delta W}^{T W}(\varepsilon)=0$.

So we have:

\section{Proposition 3}

When there are two mutually exclusive actions $(j=1,2)$ that a firm might take, with 0 $<\mu_{1}<\mu_{2}<1 / 2$, and there are marginal cost-reducing efficiencies, $\Delta c>0$, there is one interval of environments, $\underline{\varepsilon}_{2}<\varepsilon<\underline{\varepsilon}_{1}$ for which welfare is higher under a CS standard. The intuition is that such a standard induces firms to undertake the less profitable action 1 thus generating higher total welfare.

There is another interval $\underline{\varepsilon}_{1}<\varepsilon<\bar{\varepsilon}_{1}$ for which welfare is lower under a CS standard since this standard forces firms to do nothing, so generating zero change in welfare whereas under a TW standard there is always one non-trivial welfare enhancing action that will be chosen and this generates positive increase in welfare.

For the environments with underlying competitiveness $\varepsilon<\underline{\varepsilon}_{2}$ and $\varepsilon>\bar{\varepsilon}_{1}$ the CS standard and the TW standard are equivalent in terms of outcomes: in the first case all actions are allowed under both standards and in the second case all actions are banned under both standards.

So, if there are actions that increase profits but lower consumer surplus, then using a CS standard can increase welfare in those cases where it restricts choice but still leaves firms 
with a non-trivial action they can take. However, using such a standard will lower welfare when it restricts choice to just the trivial action, while there are non-trivial actions that contribute positively to welfare.

Thus, whether on average one standard is better than the other one depends on the distribution of environments (the distribution of $\varepsilon$ when considering $\mu^{0}$ constant) and the critical values $\underline{\varepsilon}_{2}, \underline{\varepsilon}_{1}$ and $\bar{\varepsilon}_{1}$ which, in turn, depend on the extant market power, the size of marginal cost-reducing efficiencies and the parameters characterizing the actions. We turn to a consideration of these in the next sub-section.

\subsection{Effects of extant market power, marginal cost-reducing efficiencies and the difference}

\section{of the price-cost margin between actions}

So far we have considered the parameter of extant market power $\left(\mu^{0}\right)$ as a given and constant parameter and examined the choice of the optimal welfare standard under different values of $\varepsilon^{30}$. We are now interested to examine how extant market power affects the comparison between CS and TW standards. It is worth remembering that the enforcement of competition law in monopolization (US) or abuse of dominance (EU) cases is characterized by a two-stage process in which it is first established whether there is "significant" extant market power ${ }^{31}$ and only if this is the case the anti-competitive impact of the challenged action is examined. So an examination of how the magnitude of extant market power affects the comparison between CS and TW standards is very important.

We also examine the effect of a number of other important parameters, again considering two mutually exclusive actions characterized by $\mu_{1}, \mu_{2}$ and symmetric efficiency effects $\Delta c>0$. Specifically, we examine how the size of marginal cost-reducing efficiencies

\footnotetext{
${ }^{30}$ Till now $\varepsilon$ was the only parameter that characterised the different environments from which a firm would come from.

${ }^{31}$ One issue is of course, that we by-pass here, is that it is not at all clear how to interpret the term "significant" here as has been stressed, for example, by Kaplow and Shapiro (2007).
} 
affects the comparison of standards, given $\mu_{1}, \mu_{2}$ and the environment in which the action is undertaken and how the size of the difference in the market power raising effects of different actions (the difference between $\mu_{1}, \mu_{2}$ ) affects the comparison, given the size of efficiencies and the environment.

We have seen that the critical level of elasticity for each action is:

$\underline{\varepsilon}_{j}=\frac{\Delta c\left(1-\mu_{j}\right)}{\mu_{j}-\mu^{0}}$

Since as we have shown already in the previous section, for any two actions 1 and 2 , the Lyons effect appears only in the interval $\left[\varepsilon_{2}, \underline{\varepsilon}_{1}\right]$, the range of environments over which the Lyons effect holds increases/decreases as the difference $\underline{\varepsilon}_{1}-\underline{\varepsilon_{2}}$ increase/decreases. From (20) we can see that the difference $\underline{\varepsilon}_{1}-\underline{\varepsilon_{2}}$ takes the following form:

$\underline{\varepsilon}_{1}-\underline{\varepsilon}_{2}=\Delta c \frac{\left(1-\mu^{0}\right)\left(\mu_{2}-\mu_{1}\right)}{\left(\mu_{1}-\mu^{0}\right)\left(\mu_{2}-\mu^{0}\right)}$

From (21) we can see that:

Lemma 4: the difference $\underline{\varepsilon}_{1}-\underline{\varepsilon}_{2}$ increases, so the range over which the Lyons effect holds increases

(i) the higher the extant market power of the firm (given the market power enhancing effects of actions 1 and $\left.2\left(\mu_{1}, \mu_{2}\right)\right)$

(ii) The higher the marginal cost-reducing efficiencies

(iii)The higher the difference between the market power enhancing effects of the two mutually exclusive actions.

Concerning (i), as we can see from (20), when $\mu^{0}$ increase the critical values of $\underline{\varepsilon}_{j}$ for both actions $(j=1,2)$ increase. However, the critical value for the action with the lowest pricecost margin ( $\underline{\varepsilon}_{1}$ in our example) will increase more than the critical value of the more 
anticompetitive action $\left(\underline{\varepsilon}_{2}\right)$. So both $\underline{\varepsilon}_{1}$ and $\underline{\varepsilon}_{2}$ move to the right (in Figure 2) from an increase in extant market power, but $\underline{\varepsilon}_{1}$ moves even further.

Also as we have seen in the previous section in the interval $\left[\varepsilon_{1}, \bar{\varepsilon}_{1}\right]$ the CS standard is worse than the TW standard, since it forces firms to do nothing while it would be welfare enhancing to take an action. Algebraic calculations show that this difference is (with $\Delta F=0$ ):

$\bar{\varepsilon}_{1}-\underline{\varepsilon}_{1}=\Delta c \frac{\left(1-\mu_{1}\right)\left(1-\mu^{0}\right)+\sqrt{\left(1-\mu_{1}^{2}\right)\left(1-\left(\mu^{0}\right)^{2}\right)}}{\mu_{1}^{2}-\left(\mu^{0}\right)^{2}}$

From Lemma 4 (iii) the Lyons effect increases the higher the difference in the market power raising effect of the actions $\left(\mu_{2}-\mu_{1}\right)$, while from (22) the range $\bar{\varepsilon}_{1}-\underline{\varepsilon}_{1}$ is not affected by this difference ${ }^{32}$. This leads to:

\section{Proposition 4}

Given two mutually exclusive actions with $0<\mu_{1}<\mu_{2}$ and $\Delta c>0$ :

(i) The TW standard will dominate the CS standard when the difference in the market power raising effect of the actions $\left(\mu_{2}-\mu_{1}\right)$, is sufficiently small.

(ii) The CS standard will dominate the TW standard when the market power raising effect of action 2 (with the higher market power raising effect) is sufficiently larger than the market power raising effect of action 1.

Essentially, the greater the difference in the market power raising effect of the actions the greater the range of environments over which the Lyons effect holds while the range of environments over which the CS standard is worse than the TW standard remains unchanged. Thus, when two mutually exclusive actions have the same marginal cost-reducing efficiency effect but one of them increases market power much more relative to the other, a stricter standard like the CS standard will be the optimal standard as this will force firms to choose the action with the lower market power raising effect.

\footnotetext{
${ }^{32}$ Since it is not affected by $\mu_{2}$.
} 


\section{Comparison of the substantive standards on the basis of numerical simulations}

In order to make further progress in our comparison of the CS and TW standards we need to be able to compare the range of environments over which each standard will be superior. For this we have to rely on numerical simulations.

One may be tempted to say that a standard is superior if it is superior over a greater range of environments than the other standard. However this would hold only when the distribution of $\varepsilon$-environments is uniform and this is an unrealistic assumption. Below we undertake the numerical analysis in terms of elasticities $(\eta)$, rather than inverse elasticities $(\varepsilon)$, for easier comparisons. It seems reasonable to assume that elasticity values at the competitive equilibrium will be concentrated in the range between about 0,5 and about 2 . (Table 1)

We start by comparing standards for different (symmetric) cost efficiency effects

Table 1: Effect of an increase in cost efficiency effects

\begin{tabular}{|c|c|c|c|c|}
\hline \multicolumn{5}{|c|}{ Numerical example for $\mu_{1}=\frac{1}{3}, \mu_{2}=\frac{1}{2}$ and $\mu^{0}=\frac{1}{5}, \Delta F=0$} \\
\hline$\underline{\varepsilon}_{\mathbf{1}}$ & $\Delta c=0.1$ & $\Delta c=0.15$ & $\Delta c=0.2$ & $\Delta c=0.25$ \\
\hline$\overline{\boldsymbol{\varepsilon}}_{\mathbf{1}}$ & 0.5 & 0.75 & 1 & 1.25 \\
\hline$\underline{\boldsymbol{\varepsilon}}_{\mathbf{2}}$ & 2.55 & 3.82 & 5.1 & 6.37 \\
\hline$\overline{\boldsymbol{\varepsilon}}_{\mathbf{2}}$ & 0.17 & 0.25 & 0.33 & 0.42 \\
\hline $\begin{array}{c}\text { Range of elasticity values over } \\
\text { which CS standard is better } \\
\left(\underline{\boldsymbol{\eta}}_{\mathbf{1}} \text { to } \underline{\boldsymbol{\eta}}_{\mathbf{2}}\right)_{33}\end{array}$ & {$[2$ to 5.88$]$} & {$[1,33$ to 4$]$} & {$[1$ to 3,03$]$} & {$[0.8$ to 2,38$]$} \\
\hline $\begin{array}{c}\text { Range of elasticity values over } \\
\text { which TW standard is better } \\
\left(\overline{\boldsymbol{\eta}}_{\mathbf{1}} \text { to } \underline{\boldsymbol{\eta}}_{\mathbf{1}}\right)_{34}\end{array}$ & {$[0,39$ to 2$]$} & {$[0,26$ to 1,33$]$} & {$[0,19$ to 1] } & {$[0,15$ to 0,8$]$} \\
\hline
\end{tabular}

We first note that the range of elasticities over which the CS standard is better is always greater than the range of environments over which the TW standard is better, so if

$$
\begin{aligned}
& 33 \underline{\eta}_{1}=\left(1 / \underline{\varepsilon}_{1}\right) \text { and } \underline{\eta}_{2}=\left(1 / \varepsilon_{2}\right) \\
& 34 \bar{\eta}_{1}=\left(1 / \varepsilon_{1}\right)
\end{aligned}
$$


elasticities were uniformly distributed then on average it would be better to use the CS standard. However, as already noted, this is not a realistic assumption.

We also note from Table 1 , that if efficiencies are low, $\Delta c<0,15$, the range of elasticity values over which the TW standard is better are the ones more likely to hold in the competitive equilibrium and this range is reasonably large, so the TW standard is likely to be the superior standard when efficiencies are low. On the other hand, if efficiencies are quite high, $\Delta c>0,15$, the range of elasticity values over which the CS standard is better are the ones more likely to hold and this range is large, so the CS standard is going to be the superior standard when efficiencies are quite high.

The findings of Table 1 are confirmed by a large number of other numerical examples ${ }^{35}$. So we have:

\section{Proposition 5}

Given two mutually exclusive actions with $0<\mu_{1}<\mu_{2}$ and $\Delta c>0$, the CS standard will dominate a TW standard when there are large marginal cost-reducing efficiencies while the TW standard is likely to dominate when marginal cost-reducing efficiencies are small.

Let us next construct the range of environments, in terms of the value of elasticity at the competitive equilibrium, over which the CS standard or the TW standard will be superior and examine how this varies with extant market power, as in the example in Table 2 below.

Table 2: Effect of an increase in extant market power

$$
\text { Numerical example for } \mu_{1}=\frac{1}{3}, \mu_{2}=\frac{1}{2} \text { and } \Delta c=0.2, \Delta F=0
$$

\begin{tabular}{|c|c|c|c|c|c|c|}
\hline & $\mu^{0}=0.05$ & $\mu^{0}=0.10$ & $\mu^{0}=0.15$ & $\mu^{0}=0.20$ & $\mu^{0}=0.25$ & $\mu^{0}=0.30$ \\
\hline$\underline{\varepsilon}_{1}$ & 0.47 & 0.57 & 0.73 & 1 & 1.6 & 4 \\
\hline $\bar{\varepsilon}_{1}$ & 3.37 & 3.61 & 4.11 & 5.10 & 7.41 & 16.94 \\
\hline$\underline{\varepsilon}_{2}$ & 0.22 & 0.25 & 0.29 & 0.33 & 0.4 & 0.5 \\
\hline
\end{tabular}

\footnotetext{
${ }^{35}$ The results of numerical simulations undertaken in this section are available from the authors on request.
} 


\begin{tabular}{|c|c|c|c|c|c|c|}
\hline$\overline{\varepsilon_{2}}$ & 1.31 & 1.34 & 1.41 & 1.52 & 1.70 & 1.97 \\
\hline $\begin{array}{c}\text { Range of elasticity } \\
\text { values over which CS } \\
\text { standard is better } \\
\left(\underline{\boldsymbol{\eta}}_{1} \text { to } \underline{\boldsymbol{\eta}}_{2}\right)\end{array}$ & $\begin{array}{c}{[2,127 \text { to }} \\
4,54]\end{array}$ & {$[1,75$ to 4$]$} & {$[1,36$ to 3,34$]$} & [1 to 3,03$]$ & {$[0,62$ to 2,5$]$} & {$[0,25$ to 2$]$} \\
\hline $\begin{array}{l}\text { Range of elasticity } \\
\text { values over which TW } \\
\text { standard is better } \\
\left(\overline{\boldsymbol{\eta}}_{\mathbf{1}} \text { to } \underline{\boldsymbol{\eta}}_{\mathbf{1}}\right)\end{array}$ & $\begin{array}{l}{[0,29 \text { to }} \\
2,127]\end{array}$ & {$[0,27$ to 1,75$]$} & {$[0,24$ to 1,36$]$} & {$[0,19$ to 1$]$} & {$[0,13$ to 0,62$]$} & $\begin{array}{c}{[0,059 \text { to }} \\
0,25]\end{array}$ \\
\hline
\end{tabular}

A number of observations can be made in relation to Table 2 above. First, we note again that the range of elasticities over which the CS standard is better is always greater than the range of environments over which the TW standard is better. So if elasticities are uniformly distributed then on average it will be better to use the CS standard. However, this cannot be generalised and will not hold in other numerical examples. It will hold when $\left(\mu_{2}-\mu_{1}\right)$, is quite large, as indicated in Proposition 5.

Second, the difference in the two ranges of elasticities (that favouring the CS standard over that favouring the TW standard) increases as extant market power $\mu^{0}$ increases. For sufficiently high extant market power clearly the CS standard dominates the TW standard.

Since it is more reasonable to assume that elasticities will not be uniformly distributed we should note, from Table 2 , that if extant market power is low, $\mu^{0}<0,15$, the range of elasticities over which the TW standard is better are the ones more likely to hold and this range is reasonably large, so the TW standard is likely to be the superior standard when extant market power is low. On the other hand, if extant market power is quite high, $\mu^{0}>$ 0,20 , the range of elasticities over which the CS standard is better are the ones more likely to hold and this range is large, so the CS standard is going to be the superior standard when extant market power is quite high. Assuming that the difference in the market power raising 
effect of the actions $\left(\mu_{2}-\mu_{1}\right)$, is not very small, these results are confirmed by a very large number of other numerical examples. So we have:

\section{Proposition 6}

Given two mutually exclusive actions with $0<\mu_{1}<\mu_{2}$ and $\Delta c>0$ and assuming that the difference in the market power raising effect of the actions $\left(\mu_{2}-\mu_{1}\right)$, is not very small, then when extant market power is low elasticities that are more likely to hold ${ }^{36}$ are found in the ranges favoring the TW standard. On the other hand, as extant market power becomes higher both the range of elasticities over which the CS standard is superior increases relative to the range that the $T W$ standard is superior and also elasticities that are more likely to hold are found in the ranges favoring the CS standard. So the TW standard will dominate the CS standard for low extant market power while the CS standard will certainly dominate the TW standard for significant extant market power. These results are important since they suggest that in all cases where significant extant market power is a prerequisite for the enforcement of Competition Law it is best to use a CS standard ${ }^{37}$.

We now turn to the case of actions also differing in marginal cost-reducing effects.

\subsection{Extension: comparison when actions differ in efficiencies}

So far we have considered above actions which differ only in their market power effects. It is worth considering what happens in the more general case where actions differ also in the extent of their marginal cost reduction $(\Delta c)$.

As above we assume that there are just two non-trivial actions $a_{j}=\left(\mu_{j}, \Delta c_{j}\right), j=1,2$ and $0 \leq \mu^{0}<\mu_{1}<\mu_{2}<1 / 2$.

\footnotetext{
${ }^{36}$ At the competitive equilibrium.

${ }^{37}$ Essentially, all cases other than horizontal agreements or cartels. For an excellent detailed discussion of the justifications for setting the high existing market power prerequisite see Kaplow and Shapiro (2007).
} 
There are then two cases to consider:

\section{Case 1: $\Delta c_{2}>\Delta c_{1}$}

Here action 2 results in a higher price-cost margin but also a greater reduction in costs. This has two implications:

- For all environments action 2 will generate a bigger increase in profits than action 1 and so will always be chosen if both are available;

- But now it is less clear how the two actions compare from the point of view of both consumer surplus and total welfare.

If $\Delta c_{2}$ is quite close to $\Delta c_{1}$ then everything will be dominated by the increase in the price-cost margin and the previous results will go through.

Consider then the other extreme where the cost differences are very large. In particular consider the situation where $\Delta c_{2} \geq \frac{\left(\mu_{2}-\mu^{0}\right)\left(1-\mu_{1}\right)}{\left(1-\mu_{2}\right)\left(\mu_{1}-\mu^{0}\right)} \Delta c_{1}$. This implies that $\underline{\varepsilon}_{2} \geq \underline{\varepsilon}_{1}$ and so, whenever action 1 is profitable under a CS standard, so too is action 2. In this case, under a CS standard action 2 will always be chosen whenever a non-trivial action is available. Now if action 2 is profitable under a CS standard it is profitable under a TW standard, and so will be chosen when a TW standard is used. So:

- Whenever a non-trivial action is chosen under a CS standard this will be action 2 and this will also be chosen under a TW standard so generating the same level of welfare;

- However, for those environments for which $\underline{\varepsilon}_{2}<\varepsilon<\bar{\varepsilon}_{2}$ action 2 will be chosen under a TW standard while only the trivial action will be chosen under a CS standard, and so, for these environments it is certainly the case that welfare is higher under a TW standard than under a CS standard.

\section{Proposition 7}


If between two mutually exclusive actions, the cost differences are sufficiently large in favour of the action with the higher market power effect, specifically if $\Delta c_{2} \geq \frac{\left(\mu_{2}-\mu^{0}\right)\left(1-\mu_{1}\right)}{\left(1-\mu_{2}\right)\left(\mu_{1}-\mu^{0}\right)} \Delta c_{1}$ then a TW standard welfare dominates a CS standard.

\section{Case 2: $\Delta c_{2}<\Delta c_{1}$}

Here action 2 generates a greater increase in market power but lower reduction in costs than action 1. This has two implications:

- Under both a CS and a TW standard action 2 is worse than action 1 in all environments - in particular, $\underline{\varepsilon}_{2}<\underline{\varepsilon}_{1}$;

- However, it is less clear which of the two actions is more profitable.

To understand this latter point define $\beta=\sqrt{\frac{\mu_{1}\left(1-\mu_{1}\right)}{\mu_{2}\left(1-\mu_{2}\right)}}$ so $0<\beta<1$.

Then it is possible to show the following:

I. If $\beta \leq \frac{\Delta c_{2}}{\Delta c_{1}}<1$ then action 2 is more profitable than action 1 in every environment and so the analysis goes through exactly as in the simple case where $\Delta c_{2}=\Delta c_{1}=\Delta c$.

II. If $\frac{\Delta c_{2}}{\Delta c_{1}}<\beta$ then if we let $\tilde{\varepsilon}=\frac{\beta \Delta c_{1}-\Delta c_{2}}{1-\beta}$, then action 1 is more profitable than action 2 if $\varepsilon<\tilde{\varepsilon}$ while action 2 is more profitable than action 1 if $\varepsilon>\tilde{\varepsilon}$. So what matters now is how $\tilde{\varepsilon}$ relates to $\underline{\varepsilon}_{2}$ and $\underline{\varepsilon}_{1}$. In particular we have:

a. If $\tilde{\varepsilon}<\underline{\varepsilon}_{2}<\underline{\varepsilon}_{1}$ then the conclusions about the relative welfare levels under a CS standard and under a TW standard go through exactly as in the case where $\Delta c_{2}=\Delta c_{1}=\Delta c$. That is welfare is higher under a CS standard (i.e. there is a Lyons effect) if $\underline{\varepsilon_{2}}<\varepsilon<\underline{\varepsilon}_{1}$ but higher under a TW standard if $\underline{\varepsilon}_{1}<\varepsilon<\bar{\varepsilon}_{1}$. The only difference is that for $\varepsilon<\tilde{\varepsilon}$ then under both a CS standard and a TW standard action 1 is chosen and so private and social incentives are aligned. 
b. If $\underline{\varepsilon}_{2}<\tilde{\varepsilon}<\underline{\varepsilon}_{1}$ then the Lyons effect only operates for $\tilde{\varepsilon}<\varepsilon<\underline{\varepsilon}_{1}$.

c. If $\underline{\varepsilon}_{1}<\tilde{\varepsilon}$ then there is no Lyons effect and a CS standard is worse than a TW standard.

\section{Proposition 8}

The greater the cost differences in favour of the action with the lower market power effect, that is the further is $\Delta c_{2}$ below $\Delta c_{1}$ then the less likely is the Lyons effect to exist, and it may disappear altogether if $\Delta c_{2}$ lies sufficiently far below $\Delta c_{1}$.

By combining proposition 7 and 8 we see that:

\section{Corollary 1}

The greater the asymmetry in efficiencies between actions the more likely that the TW standard is the optimal standard.

This result contrasts with Proposition 5 according to which if marginal cost-reducing efficiencies are the same across actions, the CS standard will dominate the TW standard when these efficiencies are large.

\section{Concluding Remarks}

In this paper we have presented a simple but general framework within which to examine the choice between the CS and TW substantive standards for Competition Law enforcement, when this choice depends on the level of aggregate welfare generated by each standard. We have shown that, in the absence of any efficiencies the two standards lead to exactly the same outcomes. A choice between them becomes important however when there are marginal-cost reducing efficiencies: $\Delta c>0$. In this case, depending on the environment in which actions are taken, the extant market power, the difference in the market power raising effects of actions and the size or asymmetries in the efficiencies, the two standards can lead to distinctly different results. Specifically, we start by showing that there will exist market environments 
for which having a CS standard may induce firms to choose lower-profit actions that result in higher total welfare than would higher-profit actions, which would be chosen under a TW standard. However, there will be some other environments for which welfare is higher when a TW standard is used, because the CS standard may be too strict and deter firms from taking any action even though there are welfare-enhancing actions that could have been chosen.

We then examine how the range of environments over which the Lyons effect is present depends on parameters such as the extant market power of the firms, the size and asymmetry or otherwise of efficiency effects and the strength of the market power raising effect generated by different actions. We show that the CS standard will be the optimal choice, when the extant market power is significant, when the size of marginal cost-reducing efficiency effects is large and when the difference in the market power raising effects of mutually exclusive actions is large. Thus, arguments in favour of a CS standard are, ceteris paribus, more likely to be valid when the actions challenged are undertaken by firms that have significant market power to start with. This is important as it suggests that in all cases where significant extant market power is a prerequisite for the enforcement of Competition Law it is best to use a CS standard. Also, ceteris paribus, a CS standard is going to be optimal when we deal with actions that can generate substantial efficiencies.

An obvious extension to the analysis above is to adopt the framework of Katsoulacos and Ulph (2015) which allows for decision errors and delays. Since decision errors and delays in decision-making affect the extent to which firms are led to choose one action rather than another these will affect the range of environments over which the Lyons effect will hold. But to the extent that delays and decision errors might be higher for a TW standard than for a CS standard, given that under the former additional considerations need to be taken into account in order to reach a decision, this introduces a potentially different reason for choosing a CS standard even if the overall goal of policy is total welfare. 
Appendix

Figure 1

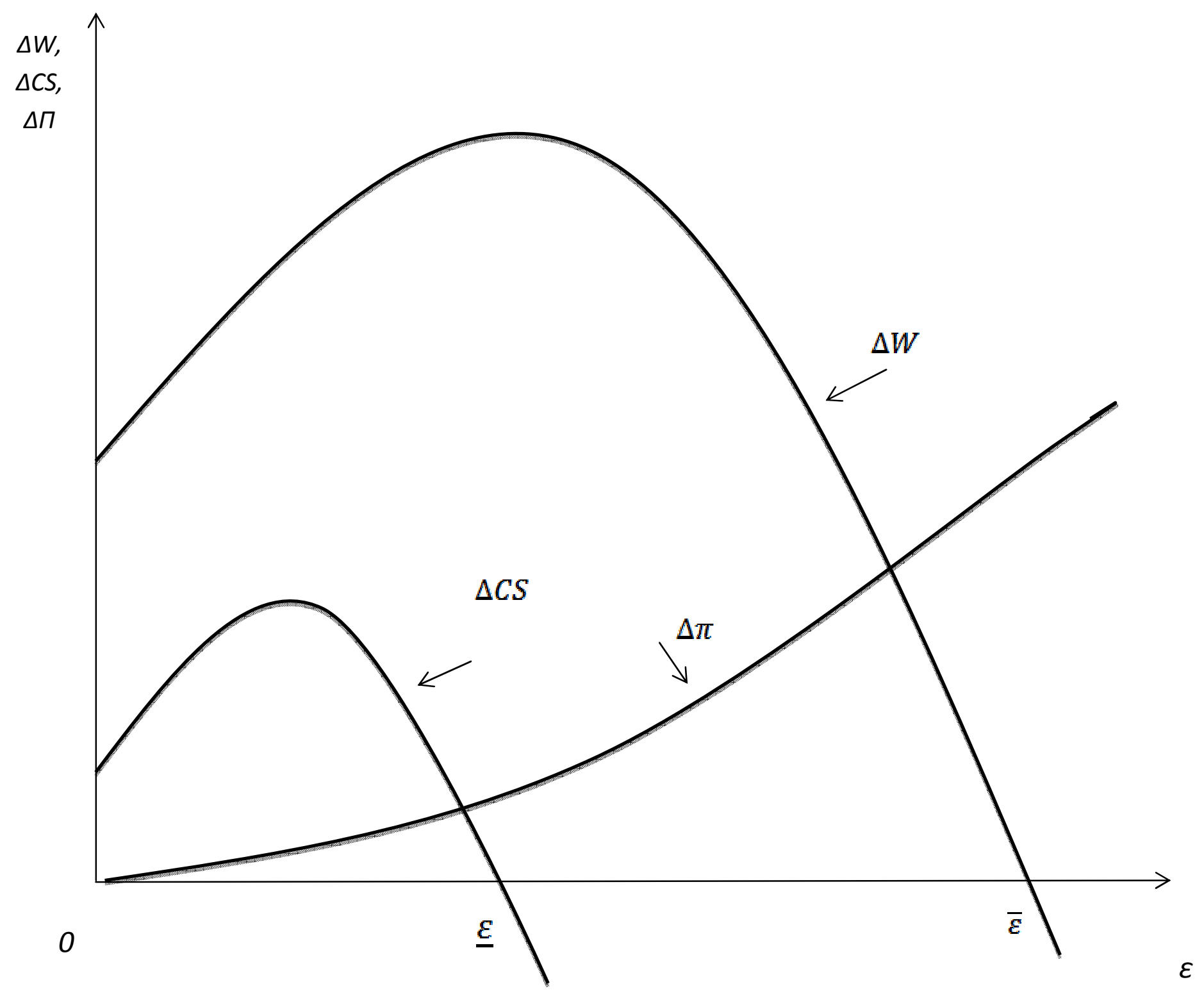


Figure 2

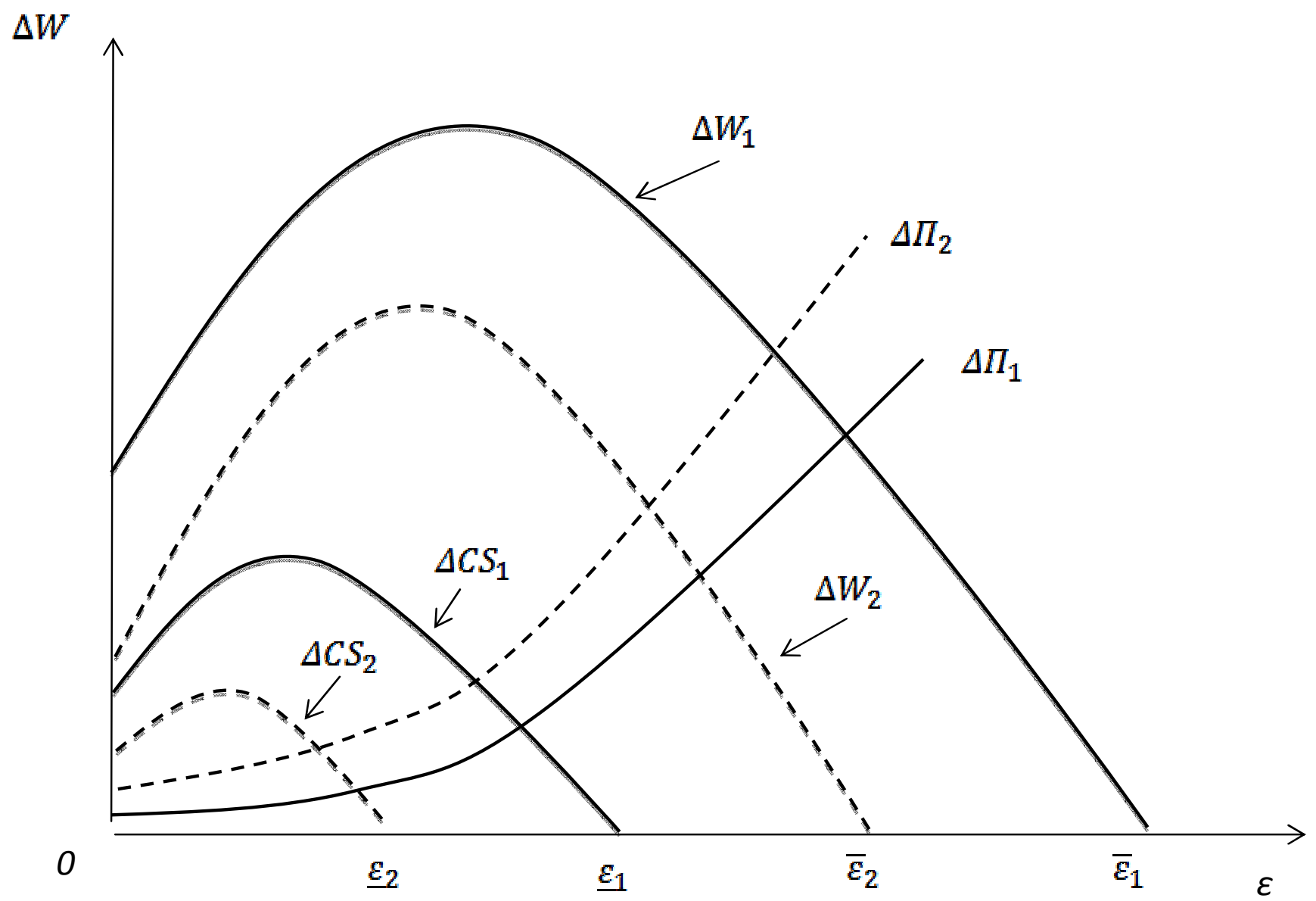




\section{ACKNOWLEDGEMENTS}

A first version of this paper appeared in May 2011. Since then we had the opportunity to present the paper in various fora and have benefitted from many comments and discussions. We would like to thank in particular the participants of the 2nd ESRC Workshop on "Optimal Enforcement Procedures" (CRESSE, Rhodes, July 3rd 2011) and especially Joe Harringtion, Bruce Lyons, Peter Møllgard, Martin Peitz, Patrick Rey, Mike Whinston and Valanta Milliou, the participants of the 10th CRETE Conference (Milos, 10 - 14 July 2011), the participants of the Microeconomics Workshop of the Dept. of Economics, AUEB (Athens, March 20th 2013), the participants of seminars in DICE, Düsseldorf Institute for Competition Economics (May 20th 2014), the Higher School of Economics and Lomonosov Moscow State University (Moscow and St Petersburg, May-June 2014) and the participants of the MaCCI Annual Conference (March 2015) and especially Andreea Cosnita-Langais, for their very useful comments. Of course all errors, omissions and inaccuracies remain our sole responsibility. Initial research was funded by an ESRC grant RES-052-23-221I "Optimal Enforcement and Decision Structures for Competition Policy" and subsequently it has been co-financed by the European Union (European Social Fund - ESF) and Greek National funds through the Operational Program "Education and Lifelong Learning" of the National Strategic reference Framework (NSRF) - Research funding program: ARISTEIA Competition, Law Enforcement and Growth. 


\section{References}

Armstrong M. and Vickers J. (2010). A Model of Delegated Project Choice, Econometrica, 78, 213-244.

Besanko D. and Spulber D. (1993). Consested Mergers and Equilibrium Antitrust Policy, Journal of Law, Economics and Organization, 9.1, 1-29.

Baker J.B. (2013). Economics and Politics: Perspectives on the Goals and Future of Antitrust, 81 Fordham L. Rev. 2175, 2184.

Baker J.B. and Salop S.C. (2015). Antitrust, Competition Policy and Inequality, mimeo, Georgetown University Law Center (http://ssrn.com/abstract=2567767).

Blair R. D. and Sokol D.D. (2013). Welfare Antitrust in US and EU Antitrust Enforcement. Fordham Law Review, 81, 2497-2541.

Carlton D. W. (2007). Does Antitrust Need to be Modernized?', Economic Analysis Group, Discussion Paper, EAG 07-3, January 2007.

Coase, R. (1960). The Problem of Social Cost, Journal of Law and Economics, 3, 1-44.

Farrell J. and Katz M. L. (2006). The Economics of Welfare Standards in Antitrust, Competition Policy Center, Institute of Business and Economic Research, UC Berkeley, July 2006.

Fox E. M. and Sullivan L. (1987). Antitrust - Retrospective and Prospective: Where Are we Coming From? Where are we Going?, 62, N.Y.U.L. Rev. 936.

Fridolsson S.-O. (2007). A Consumer Surplus Defense in Merger Control, Research Institute of Industrial Economics, IFN Working Paper No. 686, 2007.

Heyer K. (2006). Welfare Standards and merger analysis: Why not the best?, Economic Analysis Group, Discussion Paper, EAG 06-8.

Hovenkamp H. (2013). Implementing Antitrust's Welfare Goals, 81, Frdham L. Rev.2471.

Kaplow L. (2011). On the choice of welfare standards in competition law, Harvard, John M. Olin Centre for Law, Economics, and Business, ISSN 1936-5349.

Kaplow L. and Shapiro C. (2007). Antitrust, Harvard, John M. Ohlin Center for Law, Economics and Business, Discussion Paper.

Katsoulacos Y. and Ulph D. (2015). Legal uncertainty, competition law enforcement procedures and optimal penalties", European Journal of Law and Economics, June 2015, pp. 1-28.

Lyons B. R. (2002). Could politicians be more right than economists? A theory of merger standards, Centre for Competition and regulation, Working paper 02-1

Motta, M. (2004). Competition policy: Theory and practice. New York: Cambridge University Press.

Neven, D. and Roller L-H (2000). Consumer surplus versus welfare standard in a political economy model of merger control, WZB working paper FS IV 00-15(2000). Published in the International Journal of Industrial Organisation (2005), 829.

Nocke V. and Whinston M. D. (2010). Dynamic merger review, The Journal of Political Economy, 118(6), 1201-1251.

Nocke V. and Whinston M. D. (2011). Merger policy with merger choice, mimeo.

O’ Donoghue R and Padilla J. (2007). The law and economics of art.82 EC, Hart Publishing. 
Padilla, J. (2005). Efficiencies in horizontal mergers: Williamson revisited. In Issues in Competition Law and Policy, Wayne Dale Collins, ed., American Bar Association Press.

Pittman, R. (2007). Consumer surplus as the appropriate standard for antitrust enforcement, Competition Policy International. 3, 204-224.

Renckens A. (2007). Welfare standards, substantive tests, and efficiency, considerations in merger policy: defining the efficiency defense, Journal of Competition Law and Economics, 3(2), 149-179.

Rosenfeld W. (2003). Superior Propane: the Case that broke the Law - Canada's experience with efficiencies offers valuable lessons to other jurisdictions, Global Competition Review, Volume 6, Issue 9, October 2003.

Salop S.C. (2010). Question: What is the Real and Proper Antitrust Welfare Standard? Answer: The True Consumer Welfare Standard, Loyola Consumer Law Review, September 2010.

Werden G. J. (2014). Antitrust's Rule of Reason: Only Competition Matters, 72 Antitrust L. J., 713.

Whinston M. (2006). Lectures in Antitrust Economics. MIT Press.

Article 101 of the EC Treaty is available at: http://eurlex.europa.eu/LexUriServ/LexUriServ.do?uri=CELEX:12008E101:EN:NOT.

Guidance on the Commission's Enforcement Priorities in Applying Article 102 EC Treaty to Abusive Exclusionary Conduct by Dominant Undertakings, Commission of the European Communities, Brussels, 3 December 2008.

U.S. Department of Justice and the Federal Trade Commission, Horizontal Merger Guidelines, (Revised 1997) available at: http://www.justice.gov/atr/public/guidelines/horiz book/hmg1.html.

Canadian Competition Act available at http://www.laws.justice.gc.ca/eng/acts/C-34/index.html. 